\title{
Management of Flowering in Three Tropical and Subtropical Fruit Tree Species
}

\author{
Thomas L. Davenport \\ University of Florida, IFAS, Tropical Research \& Education Center, 18905 SW 280 Street, Homestead, FL 33031
}

There exist hundreds of cultivated tropical and subtropical fruit species, most of which are arboreal. Among these are mango (Mangifera indica), which thrives from the equator (zone 11) to the subtropical limits of tropical zone $10 \mathrm{~b}$ of the northern and southern hemispheres (Cathey, 1990; Jordan, 2001); Citrus sp., which have a growing range that extends for some species from near the equator into subtropical zone 9b, including, for examples California, Texas, and Florida; and lychee (Litchichinensis), which performs best at the subtropical limits of tropical zone 10b (Fig. 1). Cathey (1990), as adapted by Jordan (2001), defined tropical Zone 11 as those locations in which the average annual minimum temperature is above $4.4^{\circ} \mathrm{C}$ and which never freeze. This area is generally bounded in the north by the Tropic of Cancer $\left(23^{\circ} 27^{\prime} \mathrm{N}\right)$ and the south by the Tropic of Capricorn $\left(23^{\circ} 27^{\prime} \mathrm{S}\right)$. It includes the low altitude dry and humid tropics as well as high altitude tropics where growing temperatures are always low but within the constraints defined by Zone 11. Plants growing in areas classified as Zone $10 \mathrm{~b}$ experience average minimum temperatures of 4.4 to $1.7^{\circ} \mathrm{C}$ with occasional frosts and rare freezes. Subtropical areas include Zone 10a with average minimum temperatures of 1.6 to $-1.1^{\circ} \mathrm{C}$ and annual mild freezes and Zone $9 \mathrm{~b}$, which defines the limits of subtropical plant production. This zone experiences -1.2 to $-3.8^{\circ} \mathrm{C}$ average annual minimum temperatures and more frequent or intense freezes.

A conceptual flowering model has been described to explain the interaction of intrinsic and extrinsic factors regulating vegetative and reproductive shoot initiation and induction for both mango (Davenport and Nunez-Elisea, 1997; Davenport, 2000) and Citrus sp. (Davenport, 1990; Davenport, 2000). Lychee is another tropical fruit species that appears to follow this general flowering model (Davenport, 2000). Although all three arboreal species display different morphologies, they all seem to respond to the same environmental cues to drive phenological changes involved in growth and development. Of the three, however, only citrus is induced to flower in specific response to water stress (Southwick and Davenport, 1986). Unless stated otherwise, the events or regulation of events described hereafter refer to all three species.

Individual stems borne on branches of these trees spend most of the time in rest. Stems here refer to resting vegetative structures composed of the terminal intercalary unit resulting from the previous flush of vegetative growth (Davenport, 1990; Davenport and NunezElisea, 1997). Ephemeral flushes of shoot growth from these stems occur periodically and last $\approx 2$ weeks before returning to the resting state. Most often, these flushes are vegetative. Individual stems typically produce only one reproductive flush per year. If synchronized, the flush will occur at once in all stems throughout the canopy. More often than not, however, sections of tree canopy flush in the tropics instead of the whole, and hence may produce flowers in one section on one occasion and in other sections on other occasions until the entire canopy has flowered.
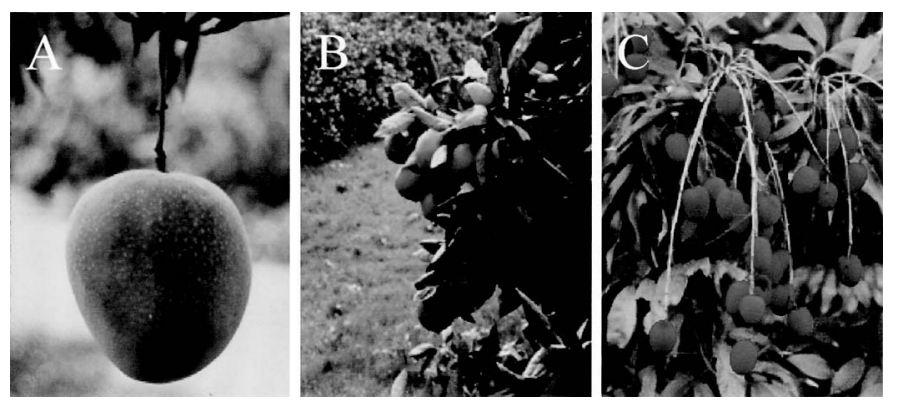

Fig. 1. (A) Mango, (B) citrus, and (C) lychee fruit.

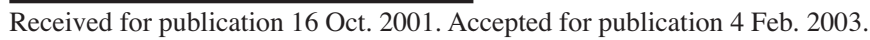

Although the subject of this article is management of flowering in these tropical fruit trees, one must first recognize that initiation of shoot growth is the first event that must occur in order to produce flowering (Davenport, 1990, 2000; Davenport and Nunez-Elisea, 1997). Management of flowering, thus, also entails management of shoot initiation. The reader is encouraged to refer to the above-cited review articles in order to fully appreciate the reasons for implementing the management practices described here.

Shoot initiation, or bud break, is driven by different factors than those regulating induction events that determine whether developing shoots will be vegetative or reproductive. It is thought to involve the interactive ratio in buds of accumulated cytokinins from roots with declining auxin production and transport from leaves of increasing age (Davenport, 2000). Frequent flush events occur in young trees and in mature trees in conditions of high nitrogen levels and an abundance of water. Other factors that stimulate initiation of shoot development include stem pruning, defoliation, foliar nitrogen sprays, and ethylene.

One of three types of shoots is typically induced to develop from initiated buds: vegetative (leaves only), generative (determinate panicle or indeterminate inflorescences), or mixed (composed of a leaf and lateral inflorescence inserted at each node or, in general, a mixture of flowers and leaves) (Fig. 2). The type of shoots that are evoked upon initiation appear to be governed by the interaction of a putative temperature-regulated florigenic promoter (FP) known to be made in leaves of mango and stem tips of citrus and an age-dependent vegetative promoter (VP), which is likely to be a gibberellin made in the same tissues as the that of the florigenic promoter of each species (Davenport, 1990, 2000, 2002; Davenport and Nunez-Elisea, 1997). The ratio of these two components in buds is thought to induce formation of the distinct shoot types; i.e., high FP to VP ratio induce generative shoots, high VP to FP ratios induce formation of vegetative shoots, and intermediate FP to VP ratios may be responsible for formation of mixed shoots.

Vegetative flushes typically occur one to three times per year on individual stems, depending upon species, cultivar, size of the tree, and growing conditions. Reproductive flushes generally occur after extended periods of stem rest in the low-latitude tropics often after relief of extended periods of non-lethal water stress or during cool winter months in the higher latitude tropics and the subtropics. Control of flowering of mango, citrus, and lychee outside of these natural flowering times focuses on management of shoot initiation at a time when the ratio of these two putative promoters are favorable for flowering.

There are reasons unique to each commodity as to why producers of mango, citrus, and lychee desire to manage flowering. Mango is perhaps the most amenable to floral manipulation. Producers are, thus, most interested in reliable out-of-season flowering in order to provide fruit

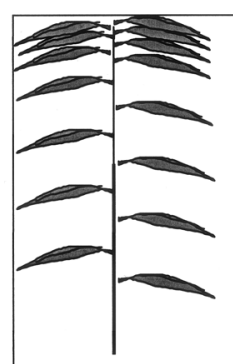

VEGETATIVE

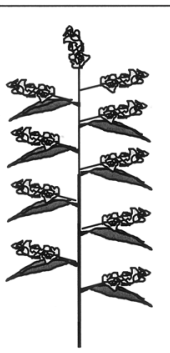

MIXED

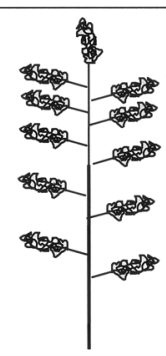

GENERATIVE
Fig. 2. Stylized diagrams of three typical shoot types representing mango, citrus, and lychee. Vegetative shoots bear only leaves. Mixed shoots bear both a leaf and inflorescence at each node. Generative shoots bear only inflorescences at each node. 
for markets at times of maximum value. Citrus is primarily produced in subtropical climates. Flowering is not an important issue in those areas unless there is concern for reduced productivity through reduced flowering as a result of annual pruning. Flowering in tropical latitudes is, however, an important issue, both for dependable flowering and for manipulation of the timing of flowering to take advantage of market opportunities. Lychee flowering has been unreliable in Florida and in other parts of the world. Growers are desperate for a management method to cause reliable flowering year after year. These issues for each commodity will be discussed separately.

\section{Out-of-season Management of Mango Flowering}

Most mango producers are interested in managing the flowering time of orchards in order to obtain early harvest. Mango prices are highest during March and April in today's markets in the northern hemisphere, and it takes about four months from flowering to fruit maturity; hence, the normal February flowering period must be shifted forward in time to October in order to accomplish harvest during this most profitable time period. Because cool arctic or antarctic winter air rarely pushes deep into low altitude, Zone 11 tropical latitudes, flowering in these regions is not governed by winter-summer cycles of low temperature, as are the subtropical Zones $9 \mathrm{~b}$ to $10 \mathrm{~b}$, which include south Florida and northern Mexico. The critical component regulating floral induction of mangoes in the tropics is the age of the last flush (Núñez-Elisea and Davenport, 1995; Davenport and Nuñez-Elisea, 1997). The older the age of the last vegetative flush (terminal intercalary unit), i.e. greater stem maturity, the more likely it is to flower when the next flush occurs. Some cultivars, such as 'Haden', require less time in rest than do others, such as 'Tommy Atkins'. Young trees and trees receiving high rates of nitrogen fertilizer in moist conditions initiate shoots frequently resulting in vegetative shoot induction due to the short periods of stem rest between flushes. Successful floral management in the tropics, thus, requires discouraging initiation of shoots before the resting stems have reached sufficient maturity to induce flowering shoots. The basis for this point was summarized by Davenport (2000).

Several operations must be performed at specific times in order for a flowering program to be successfully accomplished on an annual basis. The flowering program can be started at any time of the year regardless of the presence or absence of fruit. Other factors, however, such as harvest of the previous seasons' crop, timing of the dry and wet seasons, and high susceptibility of flowers and fruit to disease during rainy seasons, are important considerations when deciding on the starting date of the flowering program. The programs are summarized in Tables 1 and 2.

Synchronization of the vegetative growth of tree canopies in an orchard is a necessary first step in the flowering management program. Synchronous growth throughout each tree allows all of the stems in the canopy to be in the same physiological stage of maturity so that management can be most efficiently achieved uniformly throughout a section of orchard. Synchronized growth is best accomplished by tip pruning all of the stems on the trees (Tables 1 and 2). Tip pruning not only causes a uniform flush of growth throughout the canopy, it removes growth- and flower-inhibiting factors in stems derived from the previous season's flowering and fruiting panicles (Davenport, 1990, 2000; Davenport and Nunez-Elisea, 1997). It is essential that trees have adequate water at the time of pruning to facilitate a rapid flushing response because even mild water stress during the tropical dry season discourages shoot initiation.

Deeper level pruning to shape trees, cutting branches as small as $2 \mathrm{~cm}$, usually results in a second vegetative flush occurring $\approx 3$ months after the first. It is essential that there be only one flush of vegetative growth that occurs $\approx 1$ month following the synchronizing prune. The depth of the pruning cut, management of fertilizer (through monitoring of leaf nitrogen levels) during the wet season, and management of water during the dry season are important factors governing the probability of a second, undesirable flush occurring before the desired time of floral stimulation. All three factors interact to promote or discourage an early second flush. Reducing the negative impact of one factor is usually sufficient to prevent occurrence of the second flush when given ample presence of the other two. For example, reducing water availability such that the plants are under mild water deficit cause trees to flush only once following pruning regardless of depth of pruning or nitrogen levels. Likewise, reduction of leaf nitrogen levels discourages a second flush during rainy seasons.

The next step in a mango flowering management program is to decide whether to use paclobutrazol or not. The triazole plant growth retardants, paclobutrazol (Cultar 250 SC, Syngenta AG, Basel, Switzerland) and uniconazole (Sumitomo Chem. Co., Tokyo), are inhibitors of gibberellin biosynthesis (Rademacher, 1991); therefore, they reduce the levels of the putative vegetative promoter, thought to be a gibberellin. Both products are effective for assisting in floral induction with uniconazole $\approx 10$ times more effective than paclobutrazol. Both products are expensive, and they can cause permanent stunting of flushes if trees are severely pruned at any time after soil application (Davenport, 1994). These chemicals provide a strong measure of certainty that flowering will occur, when used properly, by shortening the time required between the synchronizing pruning and application of floral-stimulating nitrate sprays (Table 1) (Nartvaranant et al., 2000; Tongumpai et al., 1991; Voon et al., 1991). The triazole products provide the flexibility needed to shift the flowering time of the more-difficult-to-manage cultivars like 'Tommy Atkins' to any week of the year with less concern for early vegetative flushes. For this reason, paclobutrazol has been widely marketed throughout the tropics to stimulate mango flowering.

Either product should be applied after the onset of re-growth following pruning ( 1 to 1.5 months after prune date) depending upon cultivar. Paclobutrazol should be applied in a soil drench containing 1 to $1.5 \mathrm{~g}$ of active ingredient per meter of canopy diameter (Nartvaranant et al., 2000) if applied during the rainy season, but personal experience has shown that about half that amount is needed if applied during the dry season. It takes at least $90 \mathrm{~d}$ for either product to exert an effect in trees (Nartvaranant et al., 2000). Earlier initiation of flushes results in

Table 1. Mango flowering program using paclobutrazol or uniconazole (P) for early flowering of an easily induced cultivar (Haden) and a more difficult-to-induce cultivar (Tommy Atkins). Schedule assumes rapid flush response one month after the synchronizing pruning (SP).

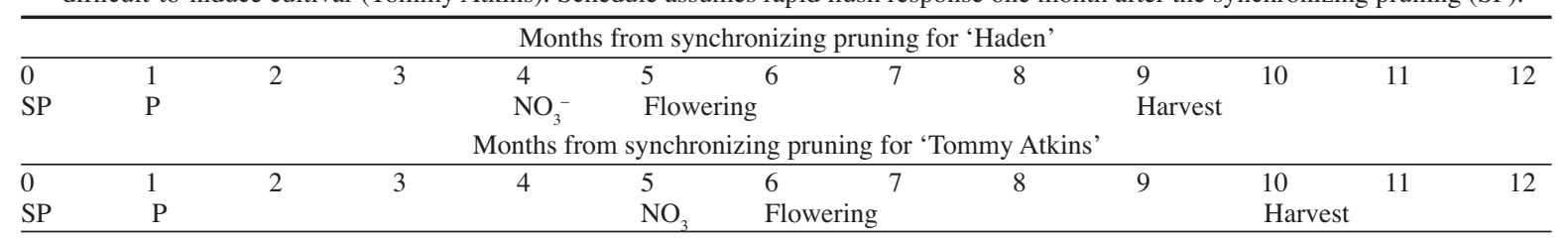

Table 2. Mango flowering program without use of paclobutrazol or uniconazole for early floral stimulation of an easily induced cultivar (Haden) and a more difficult cultivar (Tommy Atkins) Schedule assumes rapid flush response one month after the synchronizing pruning (SP).

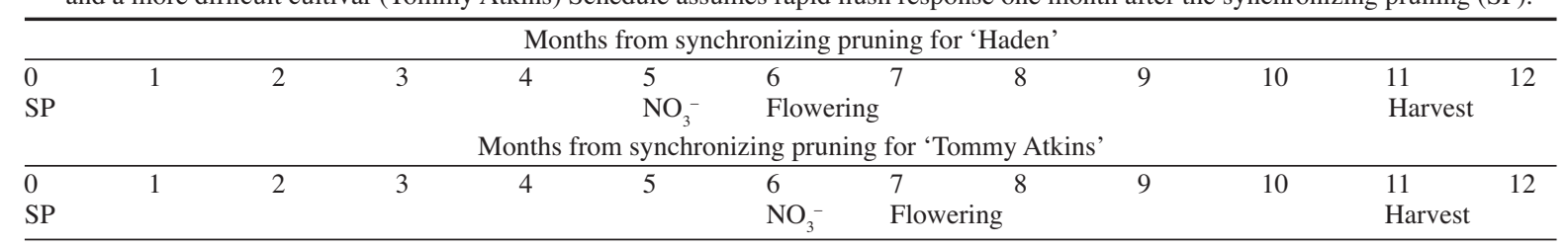


formation of vegetative shoots so it is still important to avoid growing conditions that promote initiation of frequent flushes when utilizing paclobutrazol.

More time must pass after pruning before stimulating flowering if paclobutrazol is not used (Table 2). It is easier to stimulate flowering of Haden, a Florida-selected cultivar commonly grown in Central and tropical South America, because the stems become sufficiently mature to elicit a floral response $\approx 5$ months after pruning. In contrast, 'Tommy Atkins', another Florida selection and the mainstay of the Florida mango industry, is more difficult to stimulate to flower in the American tropics. This is due to the added month of rest necessary prior to eliciting a flowering response (Tables 1 and 2).

Nitrate salts applied to foliage stimulate shoot initiation (see reviews in Davenport and Nuñez-Elisea, 1997; Davenport, 2000). Floral stimulation with nitrate application must be accomplished at the time periods indicated in Tables 1 and 2, depending upon cultivar, night temperatures at the time, and upon whether paclobutrazol is being utilized or not. Application of nitrate earlier than recommended usually results in vegetative instead of flowering flushes. Any nitrate salt or thiourea works to stimulate initiation of flowering shoots when administered at the proper time (Nuñez-Elisea, 1988; Tongumpai et al., 1997). Calcium or potassium nitrate should be spray applied to the undersides of leaves throughout the tree canopy without adjuvant as a $4 \%(\mathrm{~W} / \mathrm{V})$ solution whereas ammonium nitrate should be applied at $2 \%(\mathrm{~W} / \mathrm{V})$. If ready to respond, the entire tree will initiate growth immediately with new shoots visible by $10 \mathrm{~d}$. Repeat biweekly sprays and observations may be needed until the desired flowering response is observed. Low night temperatures occurring during the scheduled spray time may result in earlier stimulation of flowering. It is advisable to spray and observe only a few sample trees from the earliest pruned group in the orchard before spraying the entire orchard to reduce the cost of repeat sprays. If a vegetative response is observed, it means the stems are too young, likely due to a later flush of growth than anticipated following the pruning event. It is advisable to wait 3 to 4 weeks before applying nitrate to a new set of such test trees. Once a flowering response is observed, then each section of the orchard, according to the order and timing of pruning, can be sprayed.

Results correlating high leaf nitrogen levels with frequent vegetative flushes lychee (Menzel et al., 1988, 1992) are directly applicable to management of mango. It is advisable that leaf analyses should be conducted on the last flush of leaves at least one or, preferably, two times per year. If one analysis is conducted per year, it should be done just prior to the synchronizing prune. The leaf nitrogen levels for mango should be $1.1 \%$ to $1.4 \%$ at the time of the synchronizing pruning in order to avoid possible second flushes (T.L. Davenport, unpublished observation). The second analysis should be conducted just prior to floral stimulation. Sufficient nitrogen should be applied in the bulk fertilizer at the time of flowering to provide the levels needed to maintain good fruit set and development without retaining any residual nitrogen after harvest that may raise the leaf nitrogen levels for the next synchronizing prune. It is essential that the trees receive all of the necessary macro- and micronutrients for healthy growth. Appropriate levels of $\mathrm{P}, \mathrm{K}, \mathrm{Mg}, \mathrm{S}$, and minor elements are necessary, as determined by leaf analyses, while managing nitrogen in the low range in order to control the frequency of vegetative flushes.

The type of irrigation used for mangoes, as well as citrus, is an important consideration if flowering management is desired. Most growers in the tropics who have irrigation to furnish water to trees through the typical 6-month annual dry season use furrow irrigation along the tree rows (personal observation). In-row furrow irrigation has the disadvantage of providing water periodically around the base of trees. The major problem is that many roots outside the limits of the irrigation ditches never get watered during the dry season; hence, water moves from roots located in or near the irrigation ditches to not only the canopy but also out to the dry roots in response to water potential gradients in the root system (Boyer, 1985; Canny, 1995; Passioura, 1988). This backwards xylem flow towards root tips likely prevents upward xylem movement of shoot initiating hormones (cytokinins) that are synthesized in root tips (Davenport, 1990; Mok, 1994; Skene, 1975). Cytokinins instead would accumulate in the tips of the roots. Active water uptake by these roots when the first rains arrive would move the accumulated cytokinins to stem buds in the canopy, thus providing the stimulus to initiate an undesired vegetative flush when the first rains of the rainy season arrive (Oslund and Davenport, 1987).

Drip irrigation provides a constant source of water to the canopy, but it has the same disadvantage of watering only those roots that are located near emitters as does in-row furrow irrigation. Experience has shown that if a grower needs to synchronize prune the orchard during the dry season and water availability becomes limited, then the post-prune flush will not occur until arrival of the first rains (personal observations). If in-row furrow or drip irrigation is available and a post-pruning flush occurs immediately after the prune, then a second flush may occur upon arrival of the first rains, especially if leaf nitrogen levels are $>1.4 \%$. Microjet irrigation has the advantage of providing continuous water availability, but since water is distributed in an area $\geq 6 \mathrm{~m}$ in diameter to most of the roots, the entire root system remains well hydrated throughout the dry period. This discourages the flush that normally occurs after the first rain ending the dry season. Leaf nitrogen levels must be in the range specified above in order to discourage vegetative flushes that tend to occur during the rainy season, especially if that period is between the synchronizing prune event and the nitrate spray dates.

\section{Out-of-season management of citrus flowering}

Citrus (sweet orange, grapefruit, mandarin, lemon, and lime) orchards located in the subtropics generally flower reliably as a result of chilling temperatures during the winter months (Davenport, 1990 2000). Development of floral induced shoots is slow during extended periods of cool night and day temperatures but becomes more rapid as day temperatures become warmer. In contrast, flowering of citrus in the tropics is generally induced by periods of water stress during the dry season (Davenport, 1990, 2000) as opposed to mango and lychee, which are not induced to flower by low water potentials (Nuñez-Elisea and Davenport, 1994; Menzel and Simpson, 1991). Sweet orange and grapefruit grown on the northern coast of Honduras is a case in point. Flowering occurs in this region as a result of water stress that occurs during the February to April dry season (Table 3). Relief from stress by the first major rain in May causes citrus to initiate a flush of growth, producing both reproductive and vegetative shoots in June. Fruit harvest as a result of this flowering event generally occurs in November-December for 'Pineapple' sweet orange and for red-fleshed grapefruit and in January-February for 'Valencia' sweet orange.

Low market prices at the major production times have prompted growers to consider moving production to more profitable periods such as from June to August. In order to do this, flowering times need to be moved accordingly. Although it has never apparently been attempted with sweet orange, research evidence reviewed in Davenport (1990) indicates that it is likely that flowering times can be moved to months that will result in production of both 'Valencia' and 'Pineapple' fruit in June-August or any chosen time (Table 4). Powerful support for this possibility comes from the fact that some grapefruit growers are already

Table 3. Normal sweet orange flowering and production cycle of two cultivars grown in the north coast of Honduras

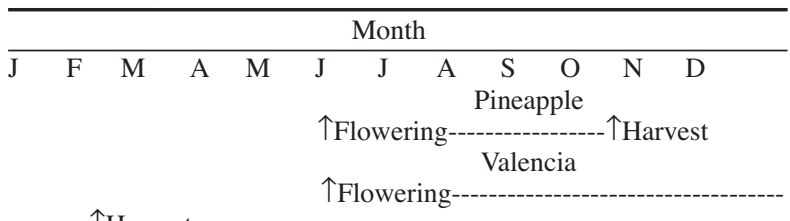

Table 4. Potential modified sweet orange flowering and production cycle of two cultivars grown in the north coast of Honduras.

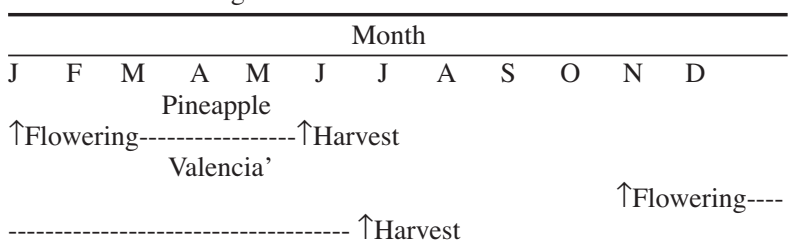


doing it (personal observation). There may be subtle differences in the performance of sweet orange from that of grapefruit, but it is highly probable that any difficulties could be overcome.

Management of three key events is critical to successfully move the flowering periods to November for 'Valencia' and January for 'Pineapple' (Table 4). The first is to prevent the normal May-June flowering and growth response to water stress by preventing water stress throughout the dry season. Irrigation must be applied to the orchard throughout the dry period so that the trees do not suffer any water deficit prior to the onset of the rainy season. As discussed earlier, irrigation of the entire root zone is an important consideration in preventing any flowering or vegetative growth in May or June.

The second event that must be managed is prevention of shoot initiation until the time when stems are sufficiently mature to induce flowering. Like mango, in the absence of low temperatures or water stress, the ability to flower is directly correlated with the age of the terminal intercalary unit in tropical climates (Davenport, 2000). The more mature the last flush is the more likely it is to produce flowering shoots when stimulated to grow; hence initiation of shoots on young terminal stems is virtually always vegetative in the absence of cool temperatures. If early shoots are initiated and become the new terminal intercalary unit, they reset the perceived age of available stems and delay a possible flowering response beyond the desired time. Management of leaf nitrogen levels is the key to controlling unwanted flushes of vegetative growth especially during the rainy season.

High nitrogen levels, especially under well-watered conditions, are conducive to initiation of frequent vegetative flushes of citrus (Jackson, 1991: Jackson et al., 1995). Reduction of vegetative flushes can be accomplished by limiting nitrogen fertilizer application to trees until the desired flowering time. It is critical to maintain annual leaf nitrogen levels sufficiently low to discourage spurious unwanted flushes of vegetative growth in the months approaching the desired flowering date. The amount of granular nitrogen necessary at flowering for good fruit set and development while preventing unwanted vegetative flushes later should be applied to root zones near the desired flowering time. Grapefruit growers in Honduras have found that application of a complete fertilizer mix containing $\approx 1.5 \mathrm{lbs} \mathrm{N} /$ tree to the orchard two months prior to the desired flowering date is appropriate for this purpose.

The third event that must be managed is stimulation of a flush of growth that will be reproductive on sufficiently mature stems. Lovatt and coworkers (Ali and Lovatt, 1994) have shown that foliar-applied, low-biuret urea (LBU) stimulated increased bud break (shoot initiation) and enhanced flowering if applied during floral inductive conditions. LBU ( $1 \% \mathrm{w} / \mathrm{v})$ coupled with the above-mentioned soil fertilizer is used to stimulate initiation of flowering shoots on mature grapefruit stems in Honduras. The LBU must be applied to the undersides of leaves for a good response. Responding stems that are sufficiently old initiate reproductive shoots about one month after application, whereas young stems initiate vegetative shoots.

Other aspects of tree maintenance, such as removal of dead branches, selective pruning, hedge or top pruning, and removal of residual fruit (especially when first starting the flowering program), should be done at the time of ground fertilizer application. All pruned branches produce only vegetative shoots due to removal of the putative florigenic promoter in stem tips (Davenport, 2002).

If each event is properly controlled, flowering should occur in each cultivar at the desired time, and normal fruit development will result in fruit harvest as has been demonstrated by July harvest of grapefruit in Honduras. The most efficient treatments, however, for sweet orange must be determined using a scientific approach. These include ascertaining the minimum age of the last flush to obtain a flowering response, optimization of leaf nitrogen levels, and determining the most efficient concentration of LBU to elicit a growth response.

\section{Reliable lychee flowering in South Florida}

Lychee (Litchi chinensis Sonn.) is gaining popularity in south Florida and is a potential alternative commercial crop in other tropical areas that experience consistently cool winters and have little danger of frost. Two primary cultivars are in cultivation, 'Mauritius' and 'Brewster'. Despite their popularity, poor and inconsistent annual yields of ly- chee trees have plagued growers in south Florida since they were first commercially planted more than 55 years ago (Young and Harkness, 1961). This is especially true for 'Brewster' since south Florida has experienced relatively mild winters during recent years.

Cool winter temperatures are known to stimulate lychee flowering (Batten and McConchie, 1995; Menzel, 1983), but it has long been believed that lychee trees also need to experience a significantly long period of vegetative dormancy as a precondition for initiating floral buds (Menzel and Simpson, 1989; Young and Harkness, 1961). Although the morphologies of lychee trees are vastly different from those of citrus and mango, the phenologies are similar (Davenport, 2000), and the interaction of environmental and endogenous cues appears to be the same as described for both mango (Davenport and Nuñez-Elisea, 1997) and citrus (Davenport, 1990)

Menzel (1983) and Menzel and Simpson (1989) estimated that a period of stem rest lasting 4 to 6 weeks prior to the winter-spring flush of lychee cultivars growing in Australia was necessary for panicle formation in that flush. Davenport and coworkers (Davenport et al., 2000; Zheng et al. 2000) have begun to quantitatively define the minimum age of lychee terminal intercalary units necessary to stimulate a flowering response in Florida when initiated during moderately cool temperature conditions. The overall results during three flowering seasons have indicated a correlative relationship between stem age, as determined by the date of the last fall vegetative flush, and the tendency for that stem to flower. The youngest of the 'Mauritius' stem ages capable of producing reproductive shoots was $\approx 10$ weeks, increasing to a peak in flowering response in stems that were between 15 and 20 weeks of age. A minimum age of nearly 15 weeks was required for 'Brewster' stems before being capable of flowering with a peak in flowering response in stems that were 20 to 25 weeks of age (Davenport et al., 2000; Zheng et al., 2000). The difference in age requirement between these two cultivars is attributed to the different latitudes in China in which they were selected (Groff, 1943; Li and Chou, 1948a, 1948b). 'Brewster' is adapted to the higher latitudes of Fukien Province in China, which experience cooler annual winter temperatures than south Florida; thus, this cultivar does not perform as well in south Florida as does 'Mauritius', which was selected in, and better adapted to, the milder winters of South China.

The importance of stem age on flowering of the subsequent flush is critical to lychee trees grown in the lower latitude tropics, such as in Honduras, where chilling temperatures are rarely experienced. Flowering can only be achieved in these areas by longer durations of stem rest than those needed in Florida where the winter temperatures typically get to $10^{\circ} \mathrm{C}$ or below for short periods.

The need to reduce the incidence of fall vegetative flushes has become even more critical for good lychee production in Florida as a result of recent warming trends. Based on the data presented above, any flushes occurring after August for 'Brewster' or September for 'Mauritius' risk a poor flowering response if the following winter temperatures are mild and cold periods are widely spaced over time. Strategies to minimize vegetative growth in the fall prior to the winter flowering season have included restriction of water or fertilizer (Menzel, 1983; Stern et al., 1998). Because abundant subterranean water in south Florida makes it difficult to restrict water availability to plants, our efforts in a complementary study have been aimed at restriction of nitrogen to minimize the probability of these fall flushes. It has long been recognized that high leaf nitrogen levels are conducive to frequent flushes of vegetative growth. Menzel and Simpson (1990) found that leaf nitrogen levels in the autumn that are $>1.7 \%$ were conducive to autumn vegetative flushes that prevented a flowering response in the winter-spring flush. In contrast, they determined that leaf nitrogen levels lower than $1.7 \%$ discouraged initiation of vegetative flushes in the fall.

Florida research on stem age has been coordinated with field experiments evaluating various levels of annual applied nitrogen on the frequency of vegetative flushes and the flowering result depending upon the age of the last flush. Four levels of applied nitrogen were: 1) $181 \mathrm{~g} \mathrm{~N} /$ year/tree applied at the onset of panicle differentiation (January); 2) $362 \mathrm{~g} \mathrm{~N} / \mathrm{year} /$ tree with one-half applied at panicle differentiation (January) and one-half applied during full flowering (March); 3) $543 \mathrm{~g} \mathrm{~N} / \mathrm{year} / \mathrm{tree}$ with one-third each applied at panicle differentiation (January), flowering (March), and after harvest (June); and 4) $724 \mathrm{~g}$ 
N/year/tree with one-fourth each applied at panicle differentiation (January), flowering (March), after harvest (July), and in November. Two applications of nitrogen applied in January, at the typical onset of winter-spring flowering in south Florida, and March have proven to provide the most reliable flowering during 3 years of research (Li et al., 2001, Li and Davenport, unpublished data). This success has been linked to the reduced levels of leaf nitrogen in the fall, which discourages fall flushes of growth. Ideally, the trees should experience one flush of vegetative growth during summer immediately following harvest. The pruning of fruit from the trees at harvest should be accompanied by pruning of non-productive, vegetative stems as well to better insure a single, synchronized flush of growth at the proper time. Low leaf nitrogen levels $(<1.5 \%)$ during fall months keep subsequent fall flushes in check until the onset of flowering the following year when nitrogen fertilizer is again applied.

\section{Conclusion}

Despite the differences in approach to managing flowering in the three groups of species described here, the overall mechanisms governing initiation and induction of flowering and vegetative shoots appear to be the same. In all of them, induction of flowering in the subtropics is primarily governed by chilling temperatures from passing cold fronts during winter-spring months. The age of the previous flush modifies the cool-temperature-induced floral response, with older stems exhibiting a higher probability of a floral response and younger stems displaying a higher probability of a vegetative response.

In the tropics, however, the age of the last flush is the dominant factor in flowering of all three species. Stems must be in rest for sufficient time, generally about 5 to 6 months to be induced to flower in the absence of chilling temperatures. This extended rest period occurs naturally as trees increase in stature, but it can also be achieved by mild plant water stress or low nitrogen fertility. Moderately cool temperatures that often reach deep into tropical dry and high elevation locations provide additional stimulus to flower in stems of a given age.

Citrus alone flowers in response to water stress. Water stress can, thus, be used as a floral promotive tool, or elimination of water stress through irrigation can be used to stimulate flowering at any other time of the year through management of stem age as discussed previously.

Armed with the basic information provided here, growers are now capable of managing the flowering times of each of these tropical fruit species. Local environmental conditions may alter the expected responses, but close scrutiny of all of the factors should bring consistent success.

\section{Literature Cited}

Ali, A.G. and C.J. Lovatt. 1994. Winter application of low-biuret urea to the foliage of 'Washington' navel orange increased yield. J. Amer. Soc. Hort. Sci. 119:1144-1150.

Batten, D.J. and C.A. McConchie. 1995. Floral induction in growing buds of lychee (Litchi chinensis) and mango (Mangifera indica). Aust. J. Plant Physiol. 22:783-791.

Boyer, J.S. 1985. Water transport. Annu. Rev. Plant Physiol. 36:473-516.

Canny, M.J. 1995. Apoplastic water and solute movement: new rules for an old space. Ann. Rev. Plant Physiol. Plant Mol. Biol. 46:215-236.

Cathey, H.M. 1990. USDA Miscellaneous Publication No. 1475. Agr. Res. Serv., U.S. Dept. Agr., Washington, D.C.

Davenport, T.L. 1990. Citrus flowering. Hort. Rev. 12:349-408.

Davenport, T.L. 1994. Potential problems with use of uniconazole on mango (Mangifera indica). PGRSA Quart. 22:143-153.

Davenport, T.L. 2000. Processes influencing floral initiation and bloom: The role of phytohormones in a conceptual flowering model. HortTechnology 10:733-739.

Davenport, T.L. 2002. Leaves not necessary for citrus floral induction. Proc. Intl. Soc. Citricult. Congr. 2000, p. 660-61.

Davenport, T.L. and R. Nuñez-Elisea. 2000. Reproductive physiology, p. 69-146. In: R.E. Litz (ed.). The Mango, botany, production and uses. CAB Intl., Wallingford, Oxon, U.K.

Davenport, T.L., Y. Li, and Q. Zheng. 2000. Towards reliable flowering of lychee (Litchi chinensis Sonn.) in south Florida. Proc. Fla. State Hort. Soc. 112:182-184

Groff, G.W. 1943. Some ecological factors involved in successful lychee culture Proc. Fla. State Hort. Soc. 56:134-155.

Jackson, L.K. 1991. Citrus growing in Florida. Univ. Fla. Press, Gainesville. $167 \mathrm{p}$.

Jackson, L.K., A.K. Alva, D.P.H. Tucker, and D.V. Calvert. 1995. Factors to consider in developing a nutrition program. p. 8. In: D.P.H. Tucker, A.K. Alva, L.K. Jackson, and T.A. Wheaton, (eds.). Nutrition of Florida Citrus Trees. Univ. Fla., Inst. Food \& Agr. Sci. Pub. SP169.

Jordan, R. 2001. USDA Plant Hardiness Zone Map. http://www.usna.usda.gov/ Hardzone/. U.S. Nat. Arboretum, Agr. Res. Serv., U.S. Dept. of Agr., Washington, D.C. 20002

Li, L.-Y. and C.-Y. Chou. 1948a. Notes on the Chen-Tze lychee of Hengwa, Fukien, China. Proc. Fla. State Hort. Soc. 61:283-284.

Li, L.-Y. and C.-Y. Chou. 1948b. Additional notes upon the history of the 'Brewster lychee. Proc. Fla. State Hort. Soc. 61:285-289.

Li, Y.C., T.L. Davenport, R. Rao, and Q. Zheng. 2001. Optimizing nitrogen to improve lychee flowering and production in south Florida. Acta Hort. 558:221-224.

Menzel, C.M. 1983. The control of floral initiation in lychee: A review. Scientia Hort. 21:201-215.

Menzel, C.M., M.L. Carseldine, and D.R. Simpson, 1988. Crop development and leaf nitrogen in lychee in subtropical Queensland. Aust. J. Exp. Agr. 28:793-800.

Menzel, C.M., M.L. Carseldine, G.F. Haydon, D.R. Simpson, 1992. A review of existing and proposed new leaf nutrient standards for lychee. Scientia Hort. 49:33-53.

Menzel, C.M. and D.R. Simpson. 1989. Unraveling some of the mysteries of lychee flowering. Queensland Fruit Veg. News, 11-13 Jan.

Menzel, C.M. and D.R. Simpson. 1990. Nutritional studies on lychee trees in subtropical Australia. Acta Hort. 275:581-585.

Menzel, C.M., Simpson, D.R. 1991. Effects of temperature and leaf water stress on panicle and flower development of litchi (Litchi chinensis Sonn.). J. Hort. Sci. 66:335-344.

Mok, M.C. 1994. Cytokinins and plant development: An overview. p. 155-166. In: D.W.S. Mok, M.C. Mok, (eds.). Cytokinins: Chemistry, activity and function. CRC Press, Boca Raton, Fla.

Nartvaranant, P., S. Subhadrabandhu, and P. Tongumpai. 2000. Practical aspects in producing off-season mango in Thailand. Acta Hort. 509:661-668.

Nuñez-Elisea, R. 1988. Nitrato de amonio: Nueva alternativa para adelantar la floracion y cosecha del mango. Campo Experimental Tecoman, Desplegable para productores No. 4. SARH-INIFAP-CIFAP, Colima, Mexico.

Nuñez-Elisea, R. and T.L. Davenport. 1994. Flowering of mango trees in containers as influenced by seasonal temperature and water stress. Scientia Hort. 58:57-66.

Núñez-Elisea, R. and T.L. Davenport. 1995. Effect of leaf age, duration of cool temperature treatment, and photoperiod on bud dormancy release and floral initiation in mango. Scientia Hort. 62:63-73.

Oslund, C.R. and T.L. Davenport. 1987. Seasonal enhancement of flower development in 'Tahiti' limes by marcottage. HortScience 22:498-501.

Passioura, J.B. 1988. Water transport in and to roots. Annu, Rev. Platn Physiol. Mol. Biol. 39:245-265.

Rademacher, W. 1991. Inhibitors of gibberellin biosynthesis: applications in agriculture and horticulture. p. 296-310. In: N. Takahashi, B.O. Phinney, and J. MacMillan, (eds.). Gibberellins. Springer-Verlag, Berlin.

Skene, K.G.M. 1975. Cytokinin production by roots as a factor in the control of plant growth. p. 365-396. In: J.G. Torrey and D.T. Calarckson, (eds.). The development and function of roots. Academic Press, New York.

Southwick, S.M. and T.L. Davenport. 1986. Characterization of water stress and low temperature effects on flower induction in citrus. Plant Physiol. 81:26-29.

Stern, R.A., M. Meron, A. Naor, R.Wallach, B. Bravdo, and S. Gazit. 1998. Effect of fall irrigation level in 'Mauritius' and 'Floridian' lychee on soil and plant water status, flowering intensity, and yield. J. Amer. Soc. Hort. Sci. 123:150-155.

Tongumpai, P., K. Jutamanee, and S. Subhadrabandu. 1991. Effect of paclobutrazol on flowering of mango cv. Khiew Sawoey. Acta Hort. 291:67-70.

Tongumpai, P., S. Charnwichit, S. Srisuchon, S. Subhadrabandu. 1997. Effect of thiourea on terminal bud break of mango. Acta Hort. 455:71-75.

Voon, C.H., C. Pitakpaivan, and S.J. Tan. 1991. Mango cropping manipulation with Cultar. Acta Hort. 291:219-228.

Young, T.W. and R.W. Harkness. 1961. Flowering and fruiting behavior of Brewster lychees in Florida. Proc. Fla. State Hort. Soc. 74:358-363.

Zheng, Q., T.L. Davenport, and Y.C. 2001. Towards [sic] reliable flowering of lychee (Litchi chinensis Sonn.) in south Florida. Acta Hort. 558:237-240. 